\title{
La profesionalización de estudiantes universitarios, a través de acciones del Colegio de Contadores Públicos, Caso: UII, UTT, CESUR de la UAS
}

\section{The professionalization of university students, through actions of the College of Public Accountants, Case: UII, UTT, CESUR of the UAS}

\author{
MARTÍNEZ-CASTRO, José David*†, JIMÉNEZ-ARTEAGA, Severo” y ULTRERAS RODRÍGUEZ, \\ Andrés
}

Instituto Irapuato. Av Mariano J. García 355, San Miguelito, Irapuato, Gto.

"Universidad Tecnológica de Tijuana. Carretera Libre Tijuana-Tecate Km 10 Fracc. El Refugio, Quintas Campestre, 22253 Redondo, B.C

Universidad Autónoma de Sinaloa, Centro de Estudios Superiores de El Rosario. Libertad s/n Col. Marcelo Loya, 82808 El Rosario, Sinaloa.

ID $1^{\text {er }}$ Autor: José David, Martínez-Castro

ID $1^{\text {er }}$ Coautor: Severo, Jiménez-Arteaga

ID $2^{\text {do }}$ Coautor: Andrés, Ultreras-Rodríguez

DOI: $10.35429 / J P D .2019 .8 .3 .1 .18$

Recibido 09 de Mayo, 2019; Aceptado 29 de Junio, 2019

\section{Resumen}

El Colegio de Contadores Públicos de Baja California, A.C. es una asociación civil afiliada al Instituto Mexicano de Contadores Públicos fue constituida mediante acta de protocolo de fecha 16 de julio de 1958 de conformidad con lo dispuesto en el Código Civil del Estado de Baja California, y es una organización que por medio de sus diferentes Comisiones regulatorias ha propiciado el mejoramiento académico de los estudiantes del programa educativos de distintas Instituciones de Educación Superior en México, encaminado a los futuros profesionales de la Contaduría hacia un ambiente propio para su desarrollo y para la consolidación de los estándares de calidad educativa. En el presente trabajo se podrá constatar con resultados palpables como es que los estudiantes han mejorado su aprovechamiento escolar desde que se adhieren de manera gratuita y voluntaria a este órgano colegiado, elevando su nivel sociocultural, logrando impactar en la eficiencia terminal y la colocación en el mercado laboral. Se describirán acciones realizadas por medio de la Comisión de Contabilidad Gubernamental que han encausado el impulso de los jóvenes estudiantes para que desarrollen favorablemente su formación integral, apoyándolos en sus aspiraciones y expectativas, capacitándolos en talleres teórico - prácticos, proporcionándoles materiales didácticos, fortaleciendo las condiciones para proveerles los espacios laborales para que incursionen en diversas etapas, desde el servicio social, las prácticas profesionales y la estadía, donde aportan sus conocimientos escolares para la solución de problemas en las empresas y por último se les promueve entre los socios del Colegio la inserción laboral en condiciones apropiadas que mejoren su económica e impulsar en ellos su participación en la sociedad cada vez más demandante, habiendo adquirido las competencias y experiencias que la profesión Contable. Esta vinculación permite asimismo a las Instituciones Educativas contar con evidencias suficientes y competentes para acceder a los procesos de evaluación y acreditación de una manera sólida y comprobable. Permite a los estudiantes ir de la mano en las prácticas profesionales con ética y valores que el Colegio de Contadores Públicos de Baja California, A.C. promueve dentro de su marco filosófico.

Programa Educativo, Contaduría, Formación Integral, Competencias, Inserción Laboral

\begin{abstract}
The College of Public Accountants of Baja California A.C is a civil association affiliated with the Mexican Institute of Public Accountants which was constituted through the protocol act dated July 18, 1958 following the regulations of the Civil Code of the state of Baja California. It is an organization that though its diverse regulated commissions have conjugated the academic improvement of the students in the Accounting program of multiple educational institutions dedicated to higher education in Tijuana Baja California Mexico, guiding the future professionals of the career into an adequate environment for their growth and consolidation of the standards of educative quality. In the presented work, the results such as that students have improved their academic achievements adhering freely and voluntarily to this collective body elevating their sociocultural level. This causing positive impact in the terminal efficiency and the placement in the labor market. They describe occurred actions through the Government Commission of Accounting that has caused an impulse in the students to develop favorably their integral formation, promoting them in theoretic workshops offering dictated materials fortifying the conditions in order to endorse various stages from social services, the professional practices where they provide their educative knowledge to solve company problems. Lastly, they are promoted, among the collage, the labor insertion under appropriate conditions that will better their economy and promote the students to participate in their communities once obtaining the experience of the accounting profession. This alignment allows for the Educative Institutions to count on enough evidence in order to allow the process of evaluation and accreditation in a solid and sustainable manner. Allowing the students to move forward hand in hand with the professional practices with ethics and values that the College of Public Accountants of Baja California A.C promotes.
\end{abstract}

Citación: MARTÍNEZ-CASTRO, José David, JIMÉNEZ-ARTEAGA, Severo y ULTRERAS RODRÍGUEZ, Andrés. La profesionalización de estudiantes universitarios, a través de acciones del Colegio de Contadores Públicos, Caso: UII, UTT, CESUR de la UAS. Revista de Didáctica Práctica. 2019. 3-8: 1-18.

\footnotetext{
*Correspondencia al Autor (Correo Electrónico: jose_martinez@correo.uii.edu.mx)

$\dagger$ Investigador contribuyendo como primer autor.
} 


\section{Introducción}

La forma como llegan los estudiantes a la Educación Superior es casi una constante en Latinoamérica, donde la educación se ha convertido en un negocio y no importa como esté preparado el aspirante, lo importante es llenar todas las aulas de clase ${ }^{1}$. Un buen ejemplo es analizar lo que sucede en México, se señala que, desde finales de los setenta, la cobertura en México creció con un fuerte contenido social, pero con componentes académicos marginales, Así, la calidad académica de los postulantes resultó secundaria frente al número de lugares disponibles y, en consecuencia, el ingreso a la Universidad se convirtió en un asunto físico más que técnico, y político más que académico Bartolucci, (1994: 35). Es necesario que las universidades privadas $\mathrm{u}$ oficiales, adopten mecanismos de selección rigurosos con el objeto de disminuir los retrasos y el abandono de los estudios, no es sorprendente que las universidades con más alto niveles de selectividad muestren la tendencia a graduar una proyección mayor de sus estudiantes, aun después de considerar las diferencias en la composición de sus alumnos Tinto, (1992:35).

Con similares propuestas se señala también que, si los estudiantes con mejor preparación académica pueden ser admitidos, la retención mejorará, probablemente. Esto es, que, si la universidad mantiene una política de admisión abierta, el desempeño se mejoraría si los alumnos de nuevo ingreso se le evalúa para determinar deficiencias académicas y de contenido, y se ofrecen alternativas remediales Metzner y Bean, (1987:34). En este sentido cabe citar la investigación sobre las competencias académicas previas y el apoyo familiar en la transición a la Universidad efectuada por Figueroa, Pilar y otros (2003) a un grupo de 1382 estudiantes que acceden a la Universidad de Barcelona (España), en ella se encontró que en concordancia con estudios anteriores sobre el proceso de transición, la importancia del contexto académico o rendimiento académico previo aparece como un factor discriminativo importante y que se puede considerar como referente importantísimo en relación a la motivación y a las expectativas de éxito académico del estudiante.

\footnotetext{
${ }^{1}$ Campas Jairo La función administrativa y la retención estudiantil en la Universidad Santiago de Cali. Direccion General de Investigaciones, 2009 p. 12

ISSN: 2523-2444

ECORFAN $^{\circledR}$ Todos los derechos reservados
}

La educación superior está sujeta a fuertes presiones a favor de un cambio ${ }^{2}$. Se le sigue exigiendo que atraiga y trabaje con estudiantes altamente calificados (los mejores y más brillantes de una generación) y que también capacite a los profesionales, investigadores y científicos de alto nivel que la sociedad necesita. $\mathrm{Y}$ aunque esto representa algunas dificultades y sin duda requiere ajustes, es lo que las universidades saben hacer y hacen bien. Al mismo tiempo, se le exige que acepte y capacite una población mucho mayor de estudiantes, con diferentes experiencias de vida, nuevas aspiraciones y calificaciones académicas generalmente inferiores, que necesitan desarrollar áreas y habilidades que hasta ahora han formado parte del currículo universitario común.

La mayoría de estos cambios y desafíos generan un impacto en la gestión institucional. La necesidad de identificar con claridad los objetivos y prioridades de la universidad, encontrar fuentes de financiamiento, la exigencia constante de responsabilidad y rendición de cuentas y el impacto de la globalización son aspectos que exigen una sólida capacidad de gestión y, en muchos casos, una revisión de las prácticas y procedimientos corrientes.

Muchos de los estudiantes que se matriculan en la educación superior provienen de escuelas más pobres de sus sistemas educacionales y cuentan con una reducida base cultural familiar y social. Esto significa que, en muchos casos, no tienen las calificaciones necesarias que se espera de ellos en términos de capacidad de comunicación, lectura, redacción y conocimiento matemático, familiaridad con otro idioma o incluso un conocimiento básico de acontecimientos históricos o sociales. Los cambios en el mercado laboral y en las carreras de los profesionales enfatizan la necesidad de desarrollar el currículo tomando en cuenta las competencias efectivas que deberán dominar los graduados cuando reciban su título.
2 Lemaitre María José "Nuevos enfoques sobre el aseguramiento de la calidad en un contexto de cambios" vicepresidenta de INQAAHE, Ex Presidenta de RIACES. 2009.

MARTÍNEZ-CASTRO, José David, JIMÉNEZ-ARTEAGA, Severo y ULTRERAS RODRÍGUEZ, Andrés. La profesionalización de estudiantes universitarios, a través de acciones del Colegio de Contadores Públicos, Caso: UII, UTT, CESUR de la UAS. Revista de Didáctica Práctica. 2019 
Nuevos enfoques pedagógicos. Los estudiantes con menos calificaciones necesitan una enseñanza que aborde sus necesidades más urgentes a fin de permitirles, más adelante, desarrollar un proceso de aprendizaje autónomo. Todo esto exige un reciclaje pedagógico que muchas instituciones no están en condiciones de ofrecer y que no es fácil de aceptar para muchos profesores de la educación superior. Desde la perspectiva institucional, la necesidad de hacerse cargo de una cantidad cada vez mayor de estudiantes cambia el peso relativo de sus funciones y convierte la enseñanza en el negocio central de la institución.

\section{Cobertura educativa matricula escolarizada en México}

\begin{tabular}{|l|c|c|c|c|c|c|c|}
\hline $\begin{array}{l}\text { Indicadores } \\
\text { del }\end{array}$ & $\mathbf{2 0 0 5 -}$ & $\mathbf{2 0 0 6 -}$ & $\mathbf{2 0 0 7 -}$ & $\mathbf{2 0 0 8}-$ & $\mathbf{2 0 0 9}-$ & $\mathbf{2 0 1 0}-$ & 2012- \\
$\begin{array}{l}\text { Programa } \\
\text { Sectorial de } \\
\text { Educación } \\
\text { 2007-2012 }\end{array}$ & $\mathbf{2 0 0 7}$ & $\mathbf{2 0 0 8}$ & $\mathbf{2 0 0 9}$ & $\mathbf{2 0 1 0}$ & $\mathbf{2 0 1 1}$ & $\mathbf{2 0 1 2}$ \\
\hline $\begin{array}{l}\text { Cobertura } \\
\text { educativa a } \\
\text { través de la } \\
\text { matrícula } \\
\text { escolarizada } \\
\text { (\% de } \\
\text { atención a la } \\
\text { demanda) }\end{array}$ & & & & & & & \\
\hline $\begin{array}{l}\text { Educación } \\
\text { Básica }\end{array}$ & 94.3 & 96.4 & 97.9 & 99.5 & 100.8 & 102.6 & 104.9 \\
\hline $\begin{array}{l}\text { Educación } \\
\text { Media } \\
\text { Superior }\end{array}$ & 58.6 & 59.7 & 60.9 & 62.3 & 64.4 & 66.7 & 68.5 \\
\hline $\begin{array}{l}\text { Educación } \\
\text { Superior }\end{array}$ & 25.2 & 25.9 & 26.7 & 27.6 & 29.1 & 30.9 & 32.4 \\
\hline
\end{tabular}

Tabla 1

Fuente: Secretaría de Educación Pública. Matriz de Indicadores de Resultados, Programa Oportunidades, Quinto Informe de Gobierno Federal

La educación superior representa una atención del $32 \%$ de cobertura educativa de la matricula escolarizada en el país en $\%$ de la atención de la demanda. Sobra decir que al final de cuentas queda menos de mitad, por la deserción y reprobación en ese nivel. Circunstancia que toma valor relevante cuando se trabaja en una gestión directiva juntamente con un colegio profesional en el área de la Contaduría Pública del Instituto Mexicano de Contadores Públicos, a través de la Comisión Gubernamental que origina resultados que se muestran en el desarrollo de este trabajo.
A continuación, se presentan gráficos derivados de los indicadores institucionales universitarios, correspondientes a los estudiantes de licenciatura en Contaduría que han sido promovidos a su afiliación a la Comisión de Estudiantes y Pasantes del Colegio de Contadores Públicos de B.C., a través del liderazgo y motivación formulada por la Comisión Gubernamental de este organismo, encaminando las acciones de la profesionalización de los estudiantes en el campo laboral de la Contaduría Pública.

\section{Matrícula Institucional}

\section{Matrícula Institucional}

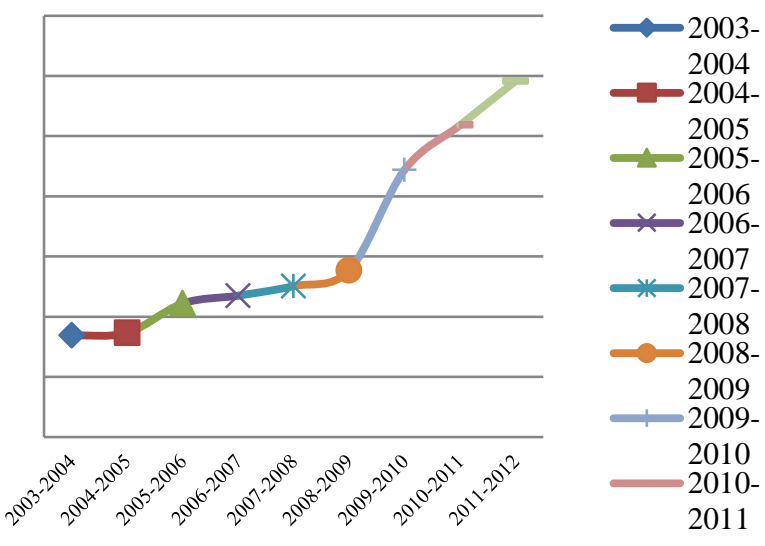

Gráfico 1

Fuente: Dirección de Evaluación y Planeación

Se observa el crecimiento constante de la matrícula, que contrasta con los bajos niveles de captación de la mayoría de las Instituciones de Educación Superior de la Región de Baja California.

\section{Alto rendimiento en EGETSU}

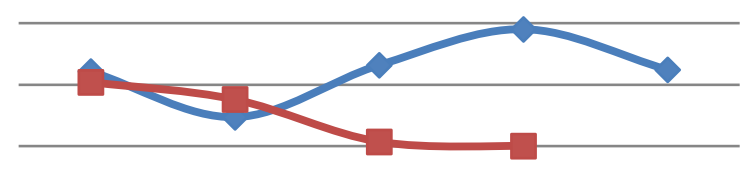

2005-2007 2006-2008 2007-2009 2008-2010 2009-2011

$\longrightarrow$ Media UTT $\longrightarrow$ Media nacional

Gráfico 2

Fuente: Dirección de Evaluación y Planeación

Se observa el grado de aprovechamiento escolar ante organismo evaluador independiente. (CENEVAL). EGETSU, es el examen general de egreso. 


\section{Matrícula de PE reconocidos por su buena calidad}

Programas Educativos Recocidos por su Buena Calidad

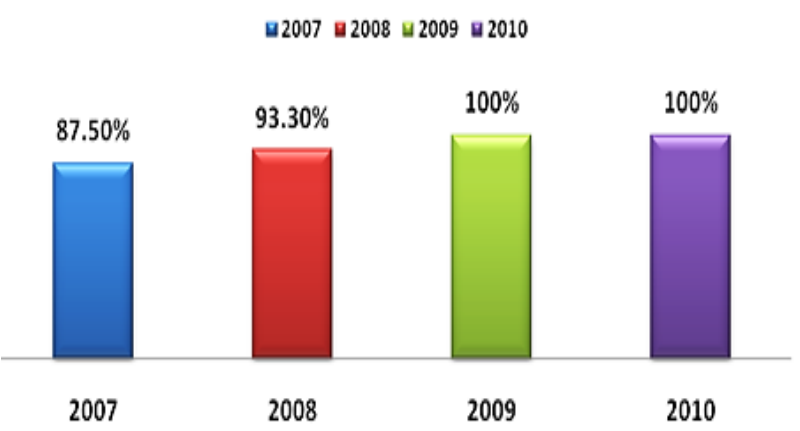

Gráfico 3

Fuente: Dirección de Evaluación y Planeación

Cuadro que muestra los programas educativos, acreditados por su buena calidad. El impulso brindado a la profesionalización es un factor que interviene en esta valoración.

\section{Captación de alumnos de nuevo ingreso}

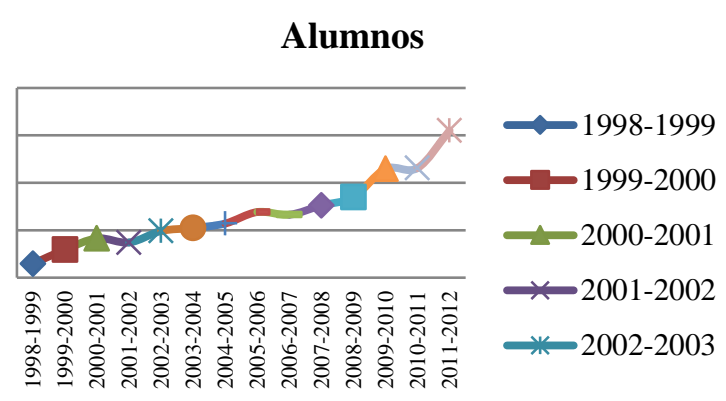

\section{Gráfico 4}

Fuente: Dirección de Evaluación y Planeación

Se observa el crecimiento constante de la matrícula de nuevo ingreso, que contrasta con los bajos niveles de captación de la mayoría de las Instituciones de Educación Superior de la Región de Baja California.

\section{Deserción}

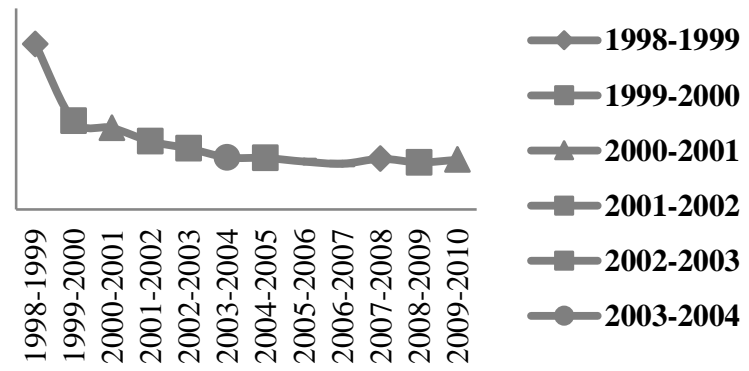

Gráfico 5

Fuente: Dirección de Evaluación y Planeación
Al trabajar de manera colegiada se contribuye a abatir la deserción escolar. Ya que el alumno percibe mayores y mejores condiciones laborales y de desarrollo profesional.

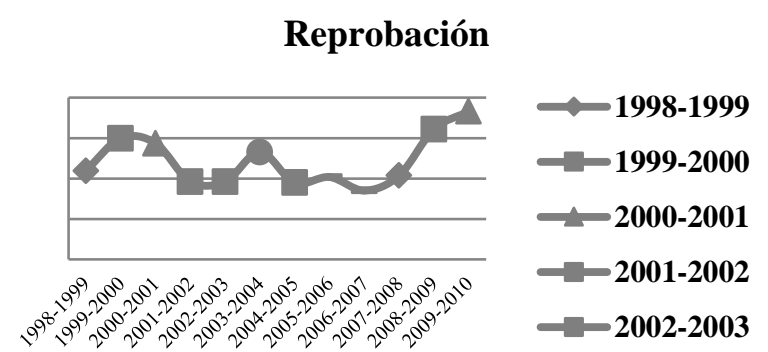

\section{Gráfico 6}

Fuente: Dirección de Evaluación y Planeación

Al trabajar de manera colegiada se contribuye a abatir la reprobación escolar. Ya que el alumno percibe mayores y mejores condiciones laborales y de desarrollo profesional.

Comparativo: PE afiliado al Colegio de Contadores Públicos y otro no afiliado

\section{Deserción ciclo escolar por Programa Educativo}

\section{Contaduría}

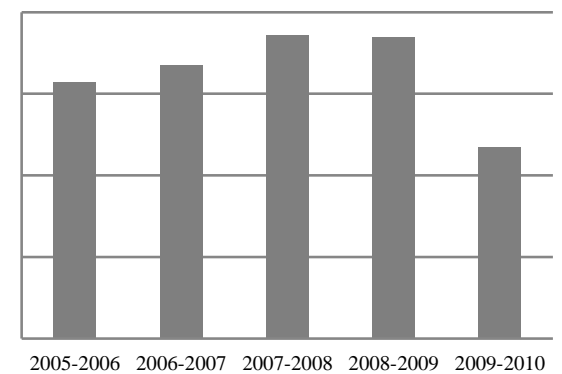

- 2005-2006

- 2006-2007

- 2007-2008

- 2008-2009

2009-2010

\section{Gráfico 7}

Fuente: Dirección de Evaluación y Planeación

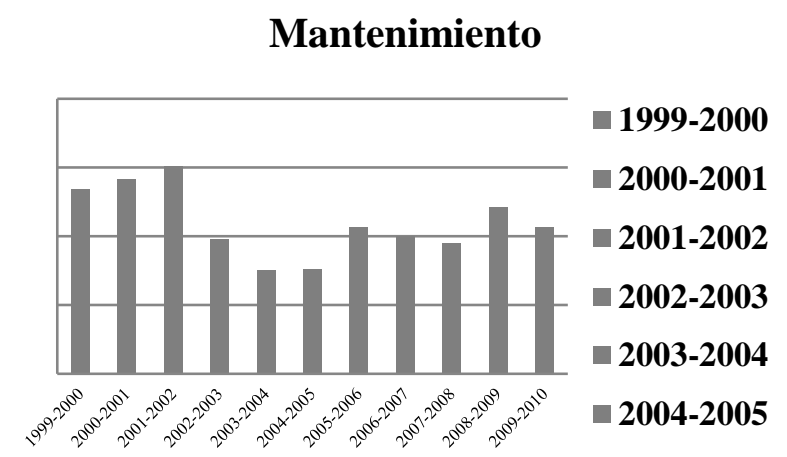

Gráfico 8

Fuente: Dirección de Evaluación y Planeación 
Se puede observar como el PE de Mantenimiento Industrial presenta una tendencia de deserción significativa constante, mientras que el PE de Contaduría logra revertir esa tendencia gracias a la estrategia de profesionalización, promovida por la Comisión Gubernamental ante el Colegio de Contadores Públicos.

Temas impartidos de capacitacion y educacion continua:

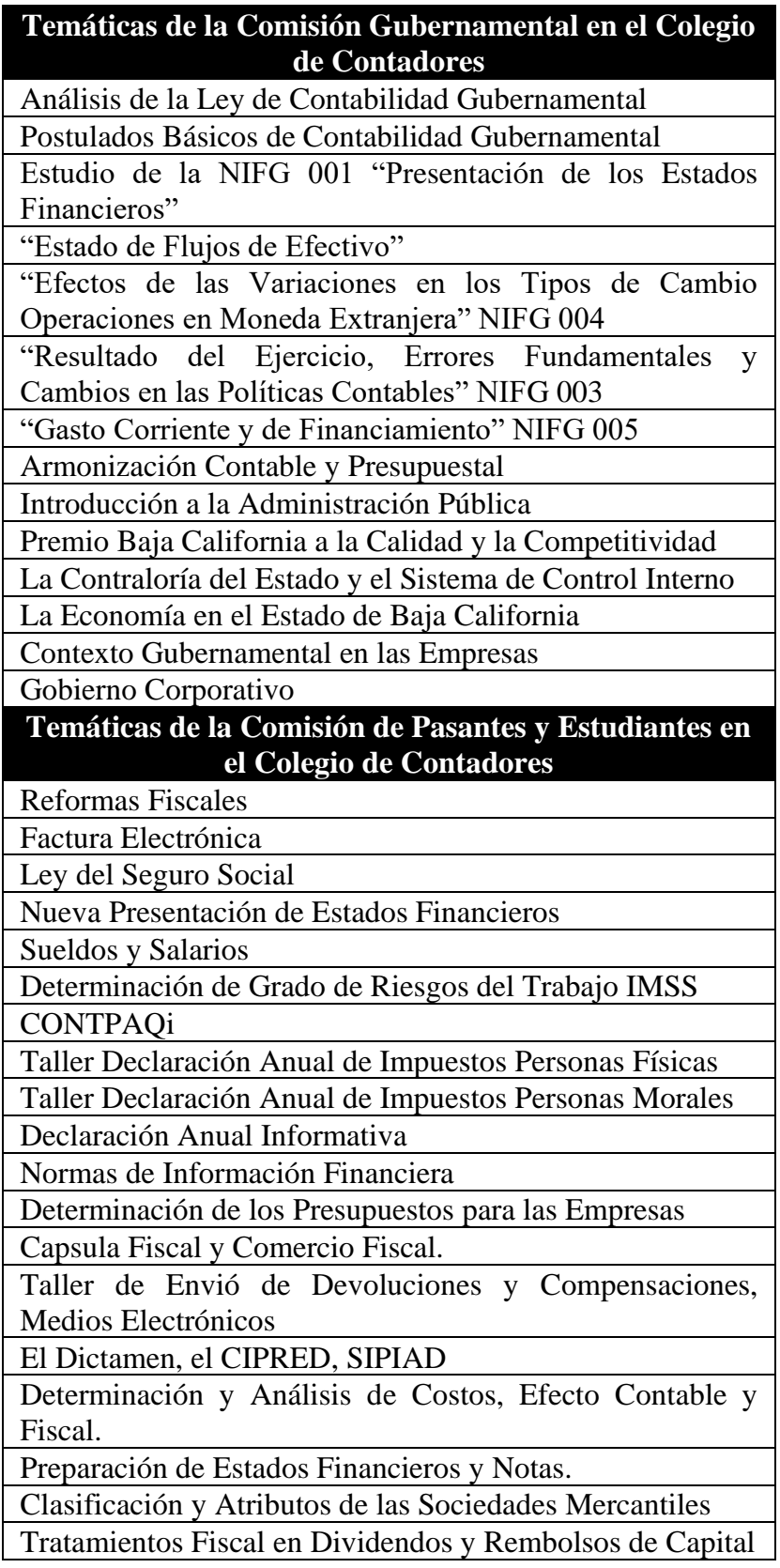

Tabla 2

Fuente: elaboración propia, que muestra un desglose de las conferencias, talleres, cursos y capacitación que se les han impartido a los estudiantes y profesores de Contaduría por parte del Colegio de Contadores Públicos de B.C., bajo la gestión de la Comisión Gubernamental, con el apoyo de la Comisión de Estudiantes y Pasantes, encaminando a los estudiantes hacia la Profesionalización.
Este trabajo se ha traducido en resultados académicos que se describen en este documento y en el proceso de fortalecimiento laboral, donde el estudiante adquiere las competencias en el aula, en el Colegio y en la Empresa.

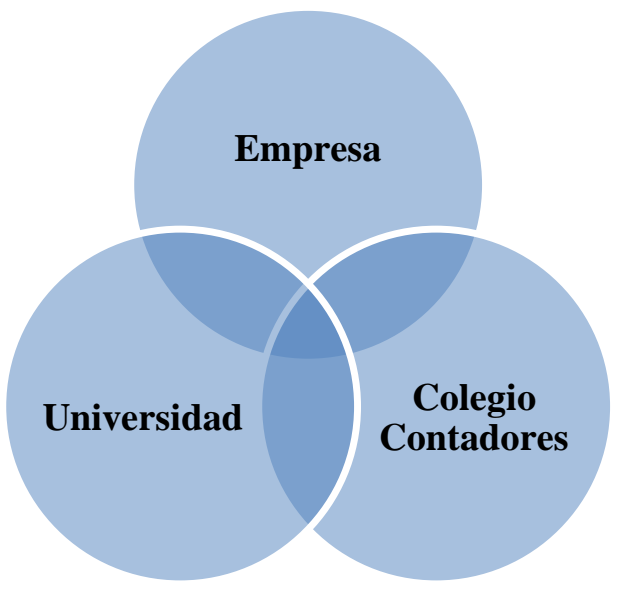

Figura 1

\section{Profesionalización}

Para contextualizar el presente trabajo, se presenta a continuación la estructura organizacional del Colegio de Contadores Públicos de Baja California, en donde se puede observar la ubicación de la Comisión Gubernamental y la Comisión de Estudiantes y Pasantes, actores principales de este documento.

Estructura Organizacional del Colegio de Contadores Públicos de B.C., A.C.

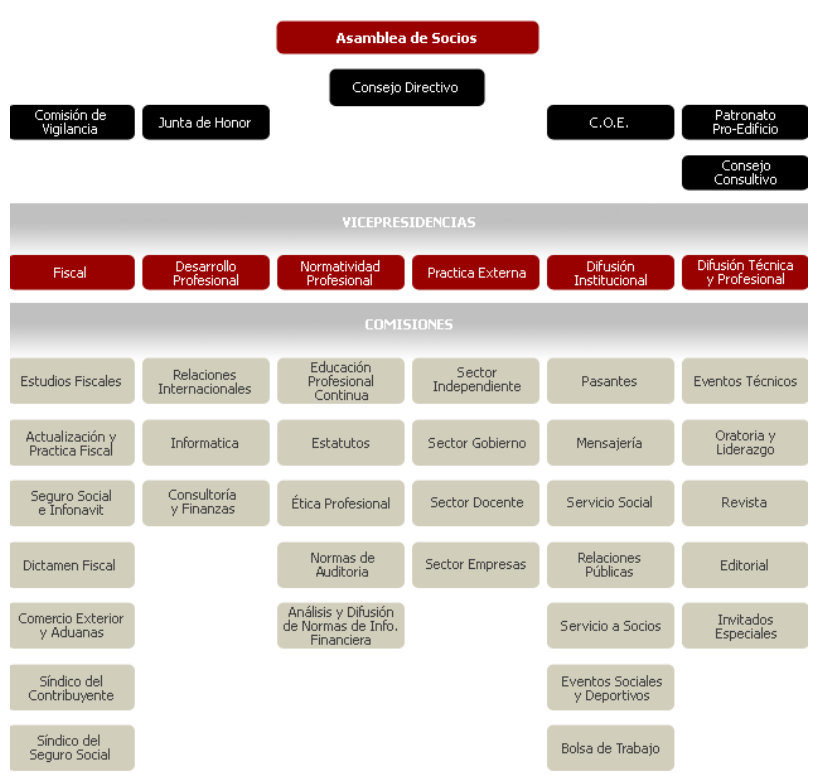

Figura 2

MARTÍNEZ-CASTRO, José David, JIMÉNEZ-ARTEAGA, Severo y ULTRERAS RODRÍGUEZ, Andrés. La profesionalización de estudiantes universitarios, a través de acciones del Colegio de Contadores Públicos, Caso: UII, UTT, CESUR de la UAS. Revista de Didáctica Práctica. 2019 
Observar las comisiones de Gobierno y de Pasantes que para el presente trabajo representan las áreas que dan sustento a la profesionalización de los estudiantes de Contaduría y que promueven su desarrollo al afiliarlos desde que son estudiantes y conducirlos en una capacitación permanente y lograr su incorporación en el sector productivo en el área de la Contaduría Pública, desarrollando su formación integral y sus competencias laborales.

Este es el diagrama del Proceso Educativo de la Universidad, donde se puede observar que no se considera la afiliación e integración de los estudiantes a una organización profesional de la Contaduría, por lo que se considera relevante el mérito de la Comisión Gubernamental y la Comisión de Pasantes y Estudiantes del Colegio de Contadores Públicos, en el complemento educativo que asegura el desarrollo integral de los prospectos profesionales.

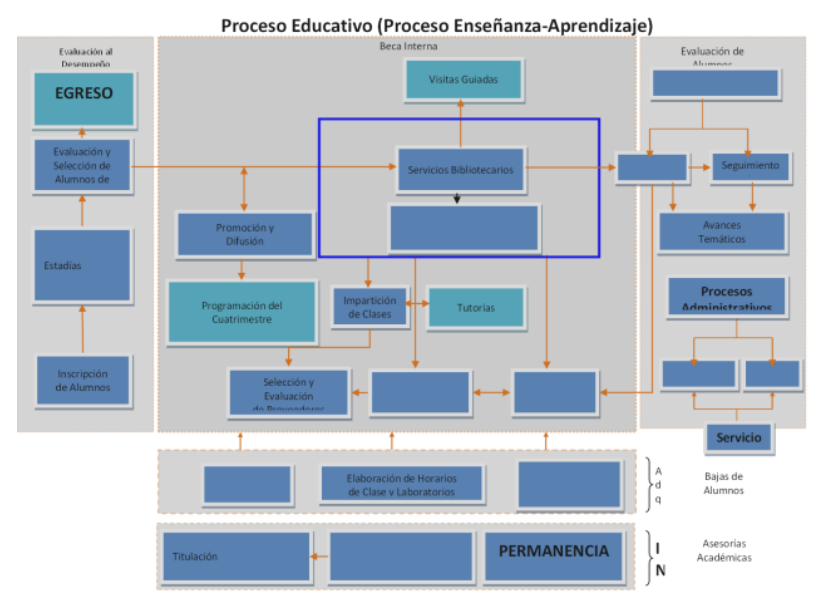

Figura 3

Fuente: Dirección de Planeación y Evaluación

A continuación, se aborda como parte sustantiva de este trabajo, la Universidad como institución formadora de Valores en los Estudiantes.

Es imprescindible que la universidad tenga como menester formar en sus alumnos un pensamiento crítico, desarrollar su creatividad y enseñarles el concepto y el proceso para la lograr la "meta-cognición", pues serán estos elementos los mecanismos centrales sobre los cuales pueda permearse en los alumnos no sólo el conocimiento sino también los valores de una ética de mínimos que el estudiante requiera para vivir en armonía y contribuir al desarrollo de su comunidad.
De acuerdo con Buxarrais (1997), una educación en valores éticos busca que los alumnos cuenten con las siguientes capacidades:

- Desarrollar estructuras universales del juicio moral y guíen su razonamiento moral por las ideas de justicia y responsabilidad.

- Adquirir competencias para dialogar democráticamente y a que este diálogo tenga como objetivo alcanzar acuerdos justos.

- Construir una imagen de sí mismos y de la vida que quieren llevar de acuerdo a los valores personales.

- Adquirir las capacidades y conocimientos necesarios para el diálogo crítico y creativo con la realidad.

- Adquirir las habilidades necesarias para hacer coherente el juicio con la acción moral.

- Reconocer y asimilar los valores universales y los derechos humanos.

- Comprender, respetar y construir normas de convivencia que regulen la vida colectiva.

Ya que la universidad busca enseñar el valor de la verdad por medio de la ciencia para responder a las preguntas: ¿qué? y ¿cómo? La universidad debe acompañar esta enseñanza de la ciencia con una enseñanza sobre los valores, pues la enseñanza de los valores guiará a los alumnos en la búsqueda de la respuesta del ¿para qué? Es la educación en los valores la que ayudará a preparar para la vida a los alumnos. Las universidades, además de transmitir conocimiento, deben formar en sus alumnos la responsabilidad ética; concientizar a los alumnos acerca de que el contenido de una materia no es bueno ni malo, sino que puede ser utilizado para el beneficio o el perjuicio de la humanidad. Para lograrlo, es necesario reconocer que la enseñanza formal de los valores, por medio de cursos curriculares es una opción para transmitir los valores a los alumnos; sin embargo, no es la única alternativa ni tampoco ha demostrado ser la más efectiva. 
El ambiente social tiene una influencia mayor de la que le ha sido reconocida, y, la mayoría de las escuelas no han desarrollado un currículo basado en las influencias sociales relacionadas con los procesos cognitivos de los estudiantes. En contraste, la globalización ha incrementado la necesidad de interacciones sociales diversas y armónicas, ¿estará la educación actual preparando a los estudiantes para ser ciudadanos exitosamente integrados a las nuevas sociedades de nuestro mundo? La enseñanza de valores puede impulsarse mediante programas extra-académicos para los alumnos y la promoción de un ambiente académico de pluralidad.

Un elemento importante en el desarrollo del estudiante se logra a través de la Tutoría como: "Una estrategia educativa que potencia la formación de profesionales"

\section{La educación con formación ${ }^{3}$}

Todos poseemos una visión más o menos acabada de lo que es educar y de cómo se debe llevar a cabo cierta labor. A esta idea general o común se le podría llamar paradigma -concepto usado por Thomas Khun (1959) y que en la actualidad se emplea con frecuencia en ámbitos académicos y de investigación. Este paradigma compartido tácticamente por la mayoría de las personas, guía el quehacer de los que participan en una institución educativa, a menudo sin reflexionar sobre él. En este sentido el paradigma es un modelo de actuación que conduce los quehaceres de la comunidad. Por eso una reflexión relativa a la tarea de educar abandona el estado de inconsciencia respecto de lo que guía nuestro hacer y, en cambio, procura conciencia $\mathrm{y}$, en su caso genera cambios en beneficio de una mayor calidad en lo educativo. Uno de los conceptos más conocidos sobre lo que es educar, considera que es el acto mediante el cual una persona (enseñante) trasmite un saber a otras (aprendices). Para contextualizar el tema de este trabajo se adopta el concepto de educación como formación consistente en un proceso de interacción, de negociación de significados, de progreso conjunto y compartido que se orienta al desarrollo integral de las personas, tomando en consideración su diversidad (Ballesteros, Margida y Comellas, 2002).

\footnotetext{
${ }^{3}$ García, F., Trejo, M. Flores, L. Rabadán, R. Educación como Formación, Capítulo I, del Libro "La Tutoría" Noriega Editores. Limusa. México, 2007

ISSN: 2523-2444

ECORFAN $^{\circledR}$ Todos los derechos reservados
}

Formar implica que la instrucción ocurre en determinados campos del conocimiento, pero, además, involucra todas las dimensiones del ser, incluidas sus diferentes potencialidades personales. El sujeto es llevado a lograr una resignificación tanto de lo aprendido como del proceso educativo, teniendo además un papel activo: revalora la experiencia y aporta elementos nuevos a la misma desde su saber y perspectiva. En esta acepción, se entiende el concepto de formar como una actividad educadora no parcial, es decir, amplia y totalizadora, de carácter externo e interno. Se procura una formación cuando se participa en el logro de la evolución del ser; es propiciar un desarrollo orientado a fines relevantes y acordados por la colectividad y el propio individuo. Es un proceso que permite la transformación de los sujetos. En la formación se busca junto con el otro las condiciones óptimas para un saber que se recibe e interioriza, con la posibilidad de ser superado y exteriorizado de nuevo, pero ahora enriquecido y con significado para el sujeto. Es una dinámica exteriorizado - interiorizado exteriorizado que transforma a las personas, a la colectividad de la que forma parte y a la cultura que construyen-. Formar es: "Entrar en contacto con "Saberes" del exterior, interiorizarlos y resignificarlos para exteriorizarlos de nuevo".

La formación se vincula con la cultura, y el hombre es capaz de recrearla. Es así como se posibilita transformar en experiencia significativa lo cotidiano en el contexto de un proyecto que es a la vez personal y colectivo. En este sentido, la formación no es algo que se logra de una vez por todas, o lo que se posee cuando se obtiene un título profesional: es una función del ser humano que se cultiva, puede desarrollarse de forma permanente y no está sujeta a edades especificas (Moreno Boyardo, 2000).

\section{La Contaduría Pública, como Profesión}

¿Qué es una profesión? La profesión es una actividad que realiza quien ha recibido formación universitaria relativa a una parte específica del conocimiento, con un grado de perfección que no cualquier persona puede dominar, esta actividad se desempeña a favor y al servicio de la comunidad, cubriendo una necesidad especifica de la sociedad en la que se desarrolla.

MARTÍNEZ-CASTRO, José David, JIMÉNEZ-ARTEAGA, Severo y ULTRERAS RODRÍGUEZ, Andrés. La profesionalización de estudiantes universitarios, a través de acciones del Colegio de Contadores Públicos, Caso: UII, UTT, CESUR de la UAS. Revista de Didáctica Práctica. 2019 
Capacidad para tomar decisiones. Conocimientos científicos y técnicos La alta calidad que caracteriza a los servicios profesionales solo se logra a través de los conocimientos que se adquieren durante los estudios universitarios, mismos que preparan al profesionista para cumplir adecuadamente con su misión social. Este proceso de acumulación de conocimientos y requisitos propicia que la formación de un profesionista se encuentre garantizada.

\section{Valores}

Para las personas que ejercen determinada profesión resulta indispensable contar con una corporación que fuera capaz de determinar y aplicar normas generales para sus integrantes, así como de sancionar a aquellos que no las cumplieran. Dichas corporaciones pueden ser: Colegios, asociaciones, institutos, etcétera., las que también se encargaran de vigilar por el bienestar y el correcto desarrollo de dicha profesión y velaran por el respeto a esta y su dignificación, por medio de sus profesionistas.

\section{La Contaduría Pública como profesión}

Es fácilmente identificada como profesión, ya que cumple con todos los requisitos. Cubre una necesidad social, ya que todas las entidades económicas requieren Información financiera confiable y un control estricto de esta para así poder tomar las decisiones más acertadas acerca del futuro de la empresa.

\section{Campos de actuación profesional}

Instituto Mexicano de Contadores Públicos (IMCP). Siendo el máximo organismo de la Contaduría pública en México, tiene la tarea de emitir normas y establecer reglamentos y estatutos, que rijan la conducta profesional de los contadores públicos, además de reunir en sí, el trabajo de las instituciones o colegios afiliados en cada zona del país, teniendo representatividad como el organismo profesional que norma la Contaduría.

Antecedentes: En 1917 se crea la primera Asociación de Contadores Públicos Titulados, el IMCP surge oficialmente en 1923, como Contadores Públicos Titulados de México, y en 1955 vuelve a cambiar de nombre, al que ostenta actualmente.
En 1965 el IMCP se convierte en Organismo Nacional y en 1977 se convierte en Federación de Colegios de Profesionistas, adquiriendo reconocimiento oficial.

Los objetivos de este instituto se encuentran escritos en el Capítulo I, en el Artículo $2^{\circ}$ de los Estatutos y Reglamentos del IMCP, como sigue:

Fomentar a nivel nacional el desarrollo y progreso de la profesión de Contador Público en todos los aspectos que se estimen convenientes, así como las relaciones con otras agrupaciones afines, nacionales y extranjeras, pugnando siempre por mantener el respeto y la consideración mutuos, como base de la dignificación de la propia profesión.

\section{Agrupaciones Académicas}

La Asociación Nacional de Facultades y Escuelas de Contaduría y Administración (ANFECA) que tiene su antecedente en 1959.

Temas de las Conferencias de ALAFEC. En este cuadro se abordan distintas temáticas desarrolladas en las Asambleas, proponiendo se incorpore un tema de la profesionalización, pero desde que el estudiante está en su proceso formativo, para que la formación integral y el sustento laboral lo logren de una manera más oportuna, dando seguridad al estudiante y desarrollando una sociedad mejor construida.

\begin{tabular}{|c|c|c|c|}
\hline Asamblea & Sede & Año & Temas \\
\hline I & Colombia & 1980 & $\begin{array}{l}\text { "Realidad y } \\
\text { Perspectivas de la } \\
\text { Contaduría Pública } \\
\text { en América } \\
\text { Latina". }\end{array}$ \\
\hline II & $\begin{array}{l}\text { República } \\
\text { Dominicana }\end{array}$ & 1982 & $\begin{array}{l}\text { "El Papel de la } \\
\text { Universidad en la } \\
\text { integración social } \\
\text { del Contador } \\
\text { Público en América } \\
\text { Latina" }\end{array}$ \\
\hline III & Lima Perú & 1984 & $\begin{array}{lr}\text { "El } & \text { Contador } \\
\text { Público del mañana } \\
\text { para } & \text { América } \\
\text { Latina". } & \\
\end{array}$ \\
\hline IV & $\begin{array}{l}\text { Bogotá } \\
\text { Colombia }\end{array}$ & 1986 & $\begin{array}{l}\text { "El Papel de las } \\
\text { Humanidades en la } \\
\text { Formación del } \\
\text { Contador Público", } \\
\text { "La Enseñanza de } \\
\text { la Computación en } \\
\text { la Contaduría } \\
\text { Pública" } \\
\text { "Presentación de } \\
\text { Estados Financieros } \\
\text { en Épocas de } \\
\text { Inflación". }\end{array}$ \\
\hline
\end{tabular}

MARTÍNEZ-CASTRO, José David, JIMÉNEZ-ARTEAGA, Severo y ULTRERAS RODRÍGUEZ, Andrés. La profesionalización de estudiantes universitarios, a través de acciones del Colegio de Contadores Públicos, Caso: UII, UTT, CESUR de la UAS. Revista de Didáctica Práctica. 2019 


\begin{tabular}{|c|c|c|c|}
\hline $\mathrm{V}$ & $\begin{array}{l}\text { Patagonia en } \\
\text { Argentina }\end{array}$ & 1988 & $\begin{array}{l}\text { "El Desarrollo de la } \\
\text { Contabilidad Social } \\
\text { en Latinoamérica", } \\
\text { "El } \\
\text { Abierto, Sistema } \\
\text { Opción Diferente", } \\
\text { y "El rol del } \\
\text { Contador r en } \\
\text { América Latina". }\end{array}$ \\
\hline VI & & 1992 & $\begin{array}{l}\text { "Por un contador } \\
\text { eficiente } \\
\text { comprometido con } \\
\text { la transformación } \\
\text { social de América } \\
\text { Latina", }\end{array}$ \\
\hline VII & México & 1995 & $\begin{array}{l}\text { "La Contaduría } \\
\text { profesional ante los } \\
\text { tratados } \\
\text { interamericanos } \\
\text { libre comercio". }\end{array}$ \\
\hline VIII & $\begin{array}{l}\text { Mérida, } \\
\text { México. }\end{array}$ & 2003 & $\begin{array}{lr}\text { "Bases para la } \\
\text { creación de un plan } \\
\text { de estudios para la } \\
\text { formación r del } \\
\text { Contador Público } \\
\text { en r América } \\
\text { Latina". }\end{array}$ \\
\hline IX & $\begin{array}{l}\text { La Habana, } \\
\text { Cuba }\end{array}$ & 2005 & \\
\hline $\mathrm{X}$ & $\begin{array}{l}\text { Santo } \\
\text { Domingo }\end{array}$ & 2007 & $\begin{array}{l}\text { "Ética en } \\
\text { Negocios" }\end{array}$ \\
\hline
\end{tabular}

Tabla 3

Fuente: Conferencias de

http://www.alafec.unam.mx/historia.php

Antecedentes de la educación superior, relacionada con el trabajo.

La educación superior tiene relación directa con el trabajo profesional, resultando fundamental promover el acceso equitativo a una educación de calidad, para fomentar la formación integral de los futuros profesionales, para que sean capaces de atender las necesidades que hoy en día van surgiendo en forma acelerada y globalizada, tanto en el ámbito social como en el de los negocios.
Ante este panorama la $\mathrm{UNESCO}^{4}$ convoco a una "Conferencia Mundial sobre la Educación Superior en el siglo XXI: Visión y Acción". Como parte de los preparativos de la conferencia, la UNESCO público en 1995 su documento de orientación sobre "Cambio y Desarrollo en la Educación Superior", que muestran entre los aspectos más relevantes los derechos humanos, la democracia, el desarrollo sostenible y la paz.

El capital humano es fundamental en la sociedad del conocimiento: en este tipo especial de sociedad la educación y el conocimiento tiene una relación estrecha. La educación, de la cual el conocimiento es sólo una parte, está, a su vez, ligada con otros fenómenos tales como el crecimiento económico, el empleo, el bienestar social. Mediante la educación se accede al conocimiento y éste es un insumo fundamental para el desarrollo económico y el empleo de las naciones; o también, como se ha dicho: en la sociedad del conocimiento la educación sería el centro y la escuela la institución clave (Villa y Parada, 2004, Pág. 27). Los egresados de las aulas se deberán formar en ambientes que les permitan abordar y proponer alternativas de solución a los complejos problemas del entorno, que requieren de mayores habilidades y conocimientos, en un mundo en el que los valores y actitudes son imprescindibles para garantizar la convivencia con el medio ambiente y el respeto a la diversidad (Villa y Parada, 2004, Pág.68).

En las Instituciones de Enseñanza Superior (IES) debe promoverse la transformación y expansión de la educación, la mejora de su calidad y su pertinencia. Es esencial tomar en cuenta que para resolver las principales dificultades que acechan a la sociedad del conocimiento, deben participar los gobiernos e instituciones de educación superior, así como todas las partes interesadas, comprendidos los estudiantes y sus familias, los profesores, el mundo de los negocios y la industria, los sectores público y privado de la economía, los parlamentos, los medios de comunicación, la comunidad, las asociaciones profesionales y la sociedad, asumiendo mayores responsabilidades para con la sociedad y rindiendo cuentas sobre la utilización de los recursos públicos y privados, nacionales o internacionales.

${ }^{4}$ Organización de las Naciones Unidas para la Educación, la Ciencia y la Cultura.

MARTÍNEZ-CASTRO, José David, JIMÉNEZ-ARTEAGA, Severo y ULTRERAS RODRÍGUEZ, Andrés. La profesionalización de estudiantes universitarios, a través de acciones del Colegio de Contadores Públicos, Caso: UII, UTT, CESUR de la UAS. Revista de Didáctica Práctica. 2019 
Los sistemas de educación superior deben aumentar su capacidad para vivir en medio de la incertidumbre, para transformarse y provocar el cambio, para atender las necesidades sociales y fomentar la solidaridad y la igualdad; preservar y ejercer el rigor y la originalidad científicos con espíritu imparcial, por ser un requisito previo decisivo para alcanzar y mantener un nivel indispensable de calidad; y colocar a los estudiantes en el primer plano de sus preocupaciones en la perspectiva de una educación a lo largo.

Debido a lo anterior es fundamental iniciar acciones que permitan desarrollar valores en los estudiantes, como actores principales del proceso educativo, lo que permitirá trascender a la parte puramente técnica de cada profesión y tener un marco de referencia sólido, desde el cual el estudiante pueda tomar decisiones sobre el avance y el ejercicio de su profesión.

En cuanto a los aspectos culturales, actitudinales y valórales, la formación integral: considera el desarrollo armónico de todas las dimensiones del estudiante. Es decir, implica, por una parte, la formación en los conocimientos propios de la profesión y de los conocimientos básicos, aquéllos que proporcionan las herramientas intelectuales esenciales para el aprendizaje permanente y la resolución de problemas complejos que requieren la concurrencia de diversas disciplinas (Villa y Parada, 2004, Pág.74).

La anterior perspectiva, se refiere a la formación en valores humanos y sociales como: respeto, tolerancia, honestidad, responsabilidad, consideración, orden y justicia.

Como se observa, los valores son fundamentales para lograr los objetivos del modelo educativo actual, así como las características de los estudiantes. En lo que se refiere al nivel cultural de los estudiantes, éste matiza su aprendizaje y la forma en que será empleado lo aprendido. Es fundamental que el alumno cuente con las bases necesarias, en cuanto a: manejo del lenguaje, cultura general, valores y ubicación social para que logre el óptimo aprovechamiento de los contenidos teóricos y prácticos de su formación profesional, para que pueda aplicarlos con eficiencia en el contexto laboral.

\section{Conferencia Mundial sobre Educación Superior. Misiones y Funciones de la educación superior}

Artículo 1. La misión de educar, formar y realizar investigaciones

Reafirmamos la necesidad de preservar, reforzar y fomentar aún más las misiones y valores fundamentales de la educación superior, en particular la misión de contribuir al desarrollo sostenible y el mejoramiento del conjunto de la sociedad, a saber:

a) Formar diplomados altamente cualificados y ciudadanos responsables:

b) Constituir un espacio abierto para la formación superior que propicie el aprendizaje permanente, brindando una óptima gama de opciones y la posibilidad de entrar y salir fácilmente del sistema, así como oportunidades de realización individual y movilidad social con el fin de formar ciudadanos que participen activamente en la sociedad y estén abiertos al mundo, y para promover el fortalecimiento de las capacidades endógenas y la consolidación en un marco de justicia de los derechos humanos, el desarrollo sostenible la democracia y la paz.

c) Promover, generar y difundir conocimientos por medio de la investigación y, como parte de los servicios que ha de prestar a la comunidad.

d) Contribuir a comprender, interpretar, preservar, reforzar, fomentar y difundir las culturas nacionales y regionales, internacionales e históricas, en un contexto de pluralismo y diversidad cultural.

e) Contribuir a proteger y consolidar los valores de la sociedad, velando por inculcar en los jóvenes los valores en que reposa la ciudadanía democrática y proporcionando perspectivas críticas y objetivas a fin de propiciar el debate sobre las opciones estratégicas y el fortalecimiento de enfoques humanistas.

f) Contribuir al desarrollo y la mejora de la educación en todos los niveles, en particular mediante la capacitación del personal docente. 


\section{Formación e Información}

\section{La ética profesional y el compromiso ciudadano}

En el ejercicio de la profesión, es sumamente conveniente que, con un sencillo acercamiento a la realidad, se debe tener conciencia del papel que la ética, el derecho y el cumplimiento de las obligaciones.

\section{El profesionista como ciudadano ¿Qué es un ciudadano?}

Ciudadano es el hombre que proviene de la ciudad, pero más que eso es el ser que tiene conciencia de sí mismo y que, por tanto, puede autodenominarse. Este dominio racional, permite que el hombre adquiera la calidad de persona, que en el derecho civil es un sujeto que es capaz de ejercer derechos y cumplir obligaciones. Esta persona posee ciertos atributos que sirven para diferenciarlo de los demás definiendo su relación con la familia y con sus semejantes, así como el poder de la propia persona respecto a los bienes, que tiene en posesión o que son de su propiedad.

\section{¿Qué es un profesional?}

La palabra "profesión" se deriva del latín, con la preposición pro y con el verbo fateor, que significa manifestar, declarar, proclamar. De estos vocablos surgen los sustantivos, profesor, y profesión. En este sentido, la profesión tiene como finalidad el bien común o el interés público, nadie es profesional, para sí mismo, pues toda profesión tiene una dimensión social de servicio a la comunidad, que se anticipa a la dimensión individual de la profesión, la cual es de beneficio particular que se obtiene de ella. Resulta absurdo buscar el propio beneficio sin importar el beneficio comunitario, porque lo que pase en cualquier colectividad siempre afectara para bien o para mal a todos sus integrantes. Hay que recocer la importancia de la ética en la profesión y en las actividades del sector público, colaborando así en el proceso de la formación profesional, promoviendo el interés por el estudio y la práctica de los valores éticos que serán de gran utilidad en la vida como ciudadano y profesional.

\section{¿Qué es la ética?}

Algunos estudiosos de la conducta humana encuentran pequeñas diferencias en el uso de las palabras ética y moral. Esto se debe a que ambas prácticamente tienen el mismo significado y se relacionan entre sí. A saber, la palabra ética proviene del griego ethos (carácter, temperamento, hábito, modo de ser) y la palabra moral se deriva del latín mos, moris (costumbre, hábito). Ambas palabras (ethos y mos) se ubican en el terreno de la ética y hacen hincapié en el modo de conducta que es adquirido por medio del hábito $\mathrm{y}$ no por disposición natural. Según Escobar (1992) la ética nos ilustra acerca del porqué de la conducta moral y los problemas que estudia son aquellos que se suscitan todos los días en la vida cotidiana, en la labor escolar o en la actividad profesional. La ética siempre implica una reflexión teórica sobre cualquier moral, una revisión racional y critica sobre la validez de la conducta humana. La moral es cualquier conjunto de reglas, valores, prohibiciones y tabúes procedentes desde fuera del hombre, es decir, que le son inculcados o impuestos por la política, las costumbres sociales, la religión o las ideologías.

\section{El papel de profesional}

La tarea de los profesionales es contribuir al bienestar social anteponiendo las necesidades de sus clientes a las propias y manteniéndose responsables ante las normas de la competencia y la moralidad ya que, ante todo, el profesionista es un proveedor de servicios.

"La ética es entendida y proyectada en los jóvenes no solo en un discurso teórico, sino como una actitud ante el quehacer profesional" 5 Ante este panorama, se puede deducir que, mediante la generación de una educación ética, los seres humanos son capaces de tomar conciencia de la responsabilidad que implica su quehacer profesional, y, como resultado de esta conciencia, los individuos son capaces de lograr éxito.
${ }^{5}$ C.P. Y Mtro. Ricardo González, director de la Escuela Bancaria y Comercial, Campus Reforma

MARTÍNEZ-CASTRO, José David, JIMÉNEZ-ARTEAGA, Severo y ULTRERAS RODRÍGUEZ, Andrés. La profesionalización de estudiantes universitarios, a través de acciones del Colegio de Contadores Públicos, Caso: UII, UTT, CESUR de la UAS. Revista de Didáctica Práctica. 2019 


\section{Formación integral del estudiante}

"El maestro debe, en la medida en que le sea posible, ser profeta: debe escrutar los signos de

los tiempos, debe adivinar en los ojos de los jóvenes las cosas bellas que ellos verán claras mañana y que nosotros hoy vemos sólo confusamente" (Lorenzo Milani. 1976, en Martínez Rizo, Nueve Retos para la Educación Superior, 2000)

Los estudiantes del PE reciben el servicio de tutorías individuales y grupales con cobertura al $100 \%$, cursaron en su totalidad un curso propedéutico previo al ingreso a la Ingeniería y atendieron un proceso de selección, así mismo se les brindo un curso de inducción al modelo educativo y al sistema de gestión de la calidad, su etapa presencial es vespertino y permite la labor productiva.

Los estudiantes del PE han presidido la Comisión de Estudiantes y Pasantes del Colegio de Contadores Públicos, A.C. y asisten a las sesiones de las diversas comisiones de ese órgano profesional de la Contaduría Pública. Participan en eventos culturales del PE, acuden a visitas guiadas a diversas empresas de la región y asisten a las convenciones regionales de la Contaduría.

\section{Vinculación con el entorno}

Se realizan eventos donde se invitan a los padres de familia para ver los proyectos de evaluación final, ceremonia de graduación en UII, UTT y UAS y en la Semana de la Contaduría Pública en esas Universidades (UII, UTT, UAS).

Se hacen visitas guiadas a las empresas donde participan todos los alumnos y sus tutores, en este último año se han visitado empresas como Vinos L.A. Cetto, Cemex, Colegio de la Frontera Norte, Colegio de Contadores Públicos de B.C, A.C. Deloitte, Certus Laboratorio, Centro Cultural Tijuana, Fundación Internacional de la Comunidad, Grupo Farías, Abogados Tributarios, Ernst \&Young, Mojica y Compañía, Bimbo, Mazda Corporación, Nissan de México, S.A. de C.V., GMC de México, S.A de C.V., Grupo MAC, S.A. de C.V. Tequila Corralejo, Procter \& Gamble |P\&G México.
Soriana Express El Rosario, S.A., Ley Express El Rosario, EXOFAR, S.A. de C.V., Desfrut, S.A. de C.V., Operadora Costa Verde, S.A. de C.V., Citrofrut, S.A. de C.V. Se ha colocado al $100 \%$ de los alumnos en los procesos de Estadía en diversas empresas y organizaciones de la de las regiones materia del presente estudio (Irapuato, Gto., Tijuana, B.C, El Rosario y Mazatlán, Sin.). Destacando la labor profesional que se ha hecho en el Servicio de Administración Tributaria SAT y en el Instituto Mexicano del Seguro Social (IMSS), así como el INFONAVIT, asesorando a la comunidad en trámites y gestiones antes las autoridades. Se ha logrado ser la sede de los trabajos de la Semana de la Contaduría Pública por tercer año consecutivo, evento del Colegio de Contadores Públicos de Tijuana, A.C. con participación de alumnos de diversas IES, maestros, firmas de Despachos Contables y especialistas en la materia Contable, Fiscal y Financiera. Estos eventos se han organizado bajos las temáticas en "Adaptaciones Económicas de la Contaduría Pública", "Perspectivas Internacionales de la Contaduría", "La Innovación de la Profesión Contable", "Presente y futuro de la Contaduría Pública", Retos del Contador ante la Reforma Fiscal", "Contabilidad y Finanzas, en un Entorno Internacional", "Innovación, Tecnología y Tendencias de la Profesión Contable y Financiera"

\section{Instituciones Participantes Semana de la Contaduría Pública en Tijuana}

\begin{tabular}{|l|l|}
\hline UABC & Universidad Autónoma de Baja California \\
\hline ITT & Instituto Tecnológico de Tijuana \\
\hline CETYS & Centro de Enseñanza Técnica y Superior \\
\hline UTT & Universidad Tecnológico de Tijuana \\
\hline CESUN & Centro de Estudios Superiores del Noroeste \\
\hline UNIVER & Universidad de Estudios Avanzados \\
\hline CUT & Centro Universitario de Tijuana \\
\hline UDC & Universidad de las Californias \\
\hline CCPBCAC & $\begin{array}{l}\text { Colegio de Contadores Públicos de Baja } \\
\text { California, A.C. }\end{array}$ \\
\hline AMCP & Asociación Mexicana de Contadores Públicos \\
\hline AEFBC & $\begin{array}{l}\text { Academia de Estudios Fiscales de Baja } \\
\text { California }\end{array}$ \\
\hline
\end{tabular}

\section{Tabla 4}

Fuente: Propia, datos y graficas que muestran el grado de convocatoria y de participación de distintas Instituciones de Educación Superior que fueron invitadas a sumarse a estos trabajos tendientes a la Profesionalización de estudiantes bajo el liderazgo de la Comisión Gubernamental y la de Estudiantes y Pasantes del Colegio de Contadores Públicos de Baja California, A.C. 


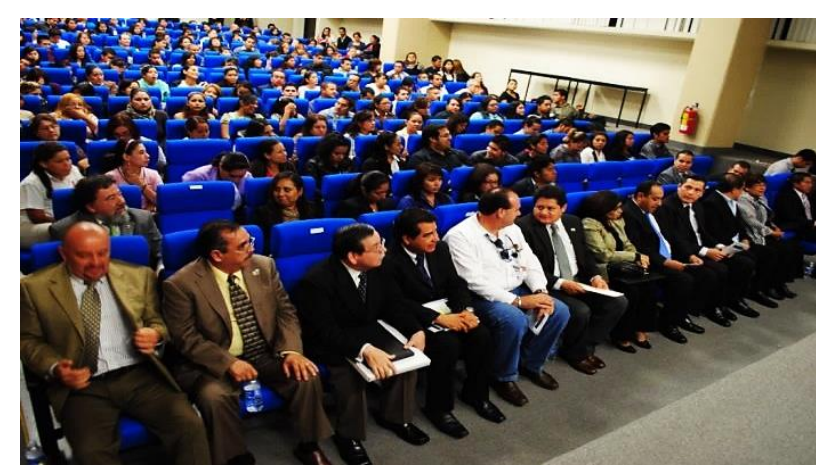

Figura 4

Fuente: elaboración propia. Ilustración que muestra el nivel de convocatoria para la asistencia a eventos técnicos programados en la Semana de la Contaduría Pública con la participación y organización de estudiantes del programa educativo de Contaduría

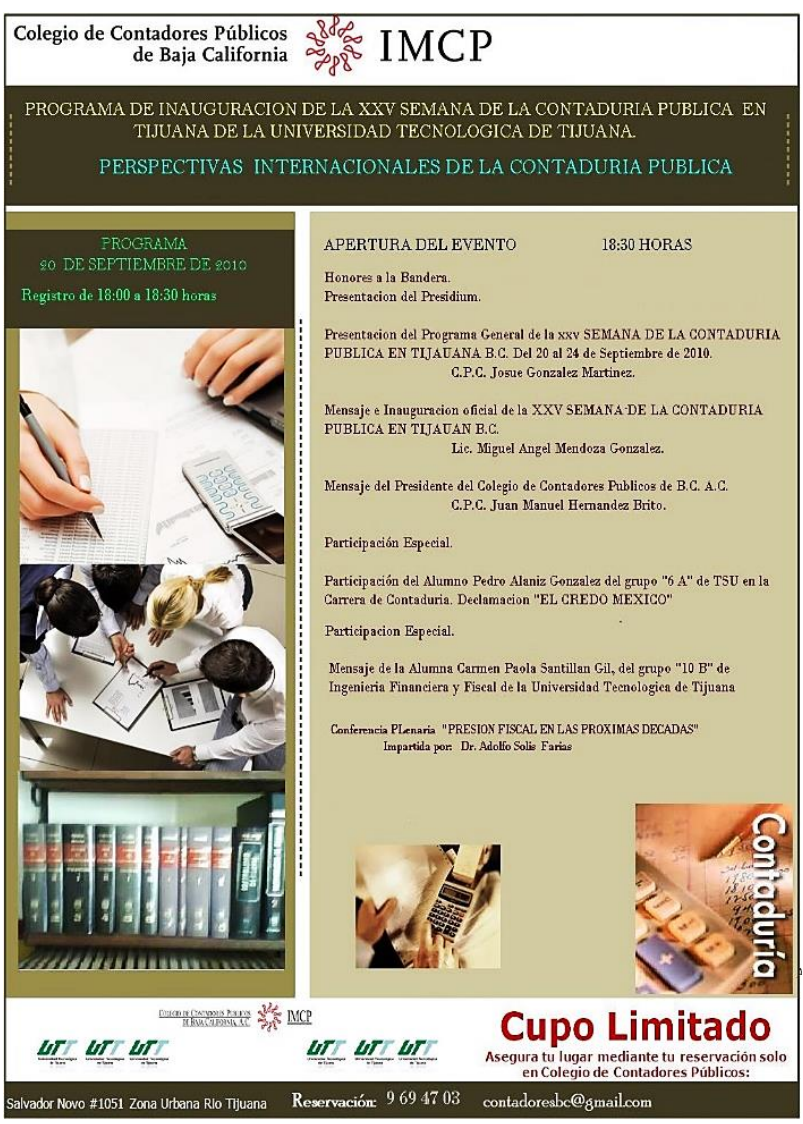

Figura 5

Fuente: elaboración propia, programa general donde participa los Estudiantes de manera activa, gratuita que tiene objetivo fortalecer sus competências y promover su vinculacion con organizaciones profesionales afiliadas al Colégio de Contadores Públicos de B.C. A.C.

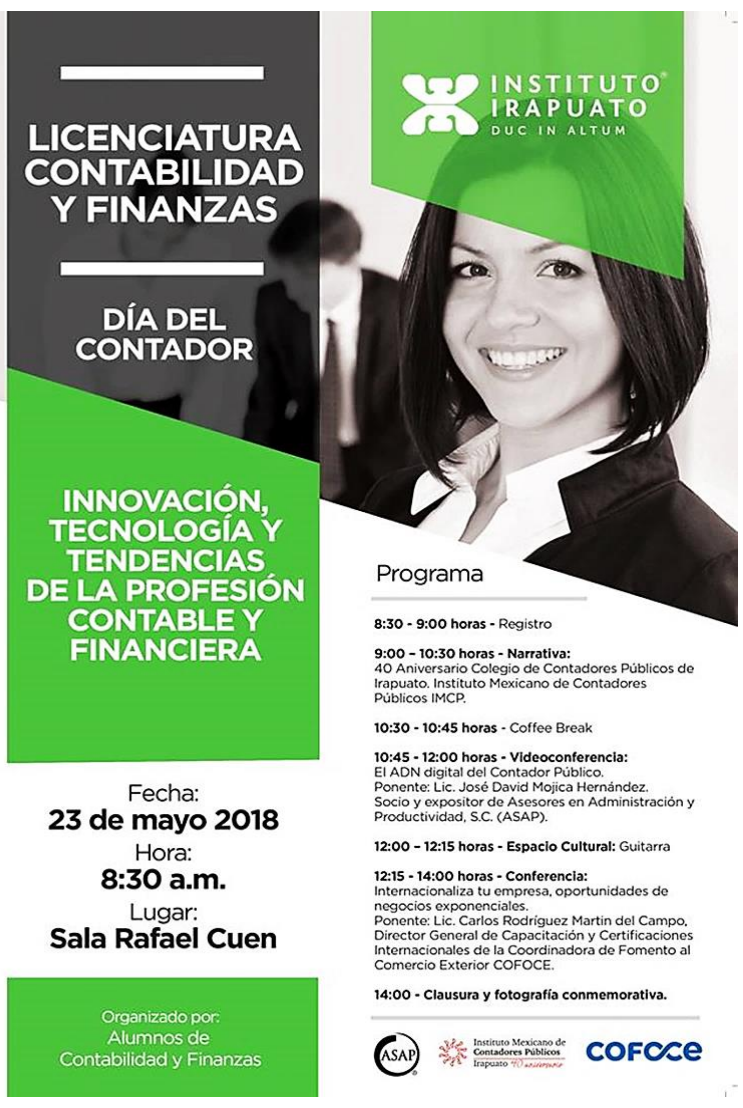

Figura 6

Fuente: elaboración propia, programa general donde participa los Estudiantes del Instituto Irapuato, de manera activa, gratuita que tiene objetivo fortalecer sus competências y promover su vinculacion con organizaciones profesionales afiliadas al Colégio de Contadores Públicos de Irapuato, A.C. 


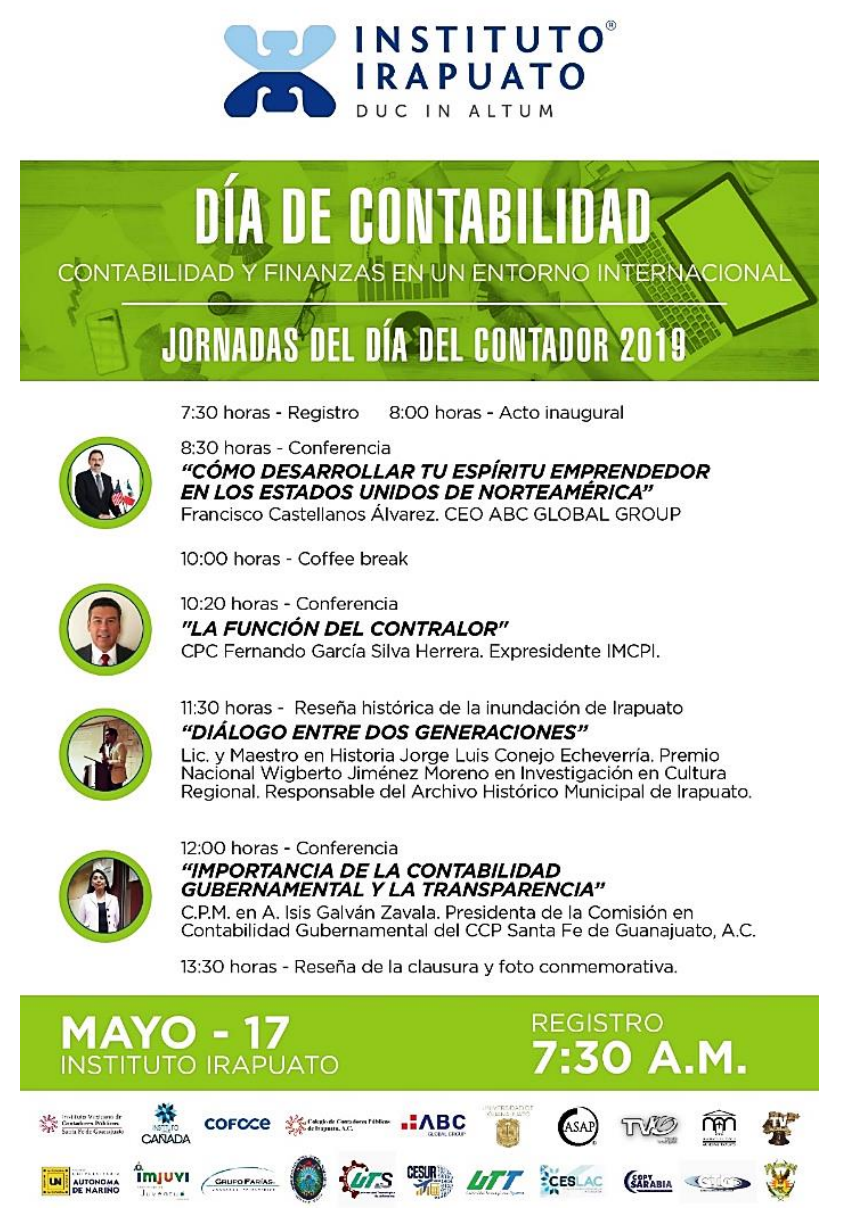

Figura 7

Fuente: Propia, programa general donde participa los Estudiantes del Instituto Irapuato, de manera activa, gratuita que tiene objetivo fortalecer sus competencias y promover su vinculación con organizaciones profesionales afiliadas al Colegio de Contadores Públicos de Irapuato, A.C

Para reforzar el marco Contextual de este organismo profesional de la Contaduría Pública, se describe a continuación aspectos normativos generales que dan sustento al marco regulatorio del Colegio de Contadores Públicos de B.C., A.C.

\section{Colegio de Contadores Públicos de Baja California, A.C.}

La Asociación Civil Constituida con la denominación de "Colegio de Contadores Públicos de Baja California, A. C." por Acta del 16 de Julio de 1958; de conformidad con las prescripciones del título Decimoprimero del Libro Cuarto, Segunda parte del Código Civil vigente para el Estado de Baja California y del Capítulo VI de la Ley Reglamentaria de los Artículos 4o. y 5o. Constitucionales, se regirá por los presentes Estatutos.

\begin{tabular}{l}
\hline El Colegio de Contadores Públicos de Baja California, \\
A.C. tiene por objeto reunir en los términos del Artículo \\
44o. de la Ley Reglamentaria de los Artículos 4o. y 5o. \\
Constitucionales, a quienes ejercen la profesión de \\
Contador Público y tendrá como propósito los siguientes, \\
contenidos en el Artículo 5o. de la propia Ley: \\
\hline Mantener la unión profesional de los Contadores \\
Públicos. \\
\hline Fomentar el prestigio de la profesión de Contador \\
Público, difundiendo el alcance de su función social y \\
vigilando que la misma se realice dentro de los más altos \\
planos de responsabilidad, idoneidad, competencia \\
profesional y moral en el cumplimiento y respeto de las \\
disposiciones legales relacionadas con su actuación. \\
\hline En suma, la misión del Colegio será: agrupar a los \\
Contadores Públicos, promoviendo y actualizando a la \\
profesión y representar ante la sociedad a sus asociados, \\
ofrecerles capacitación y otros servicios que les permitan \\
desempeñarse con excelencia en el marco de normas de \\
actuación profesional y generar recursos suficientes que \\
aseguren al Colegio mantener, mejorar y ampliar sus \\
actividades. Se considera como Contador Público las \\
diferentes denominaciones con las que las instituciones \\
de educación superior expiden sus títulos relativos a la \\
Contaduría Pública y equivalentes. \\
\hline
\end{tabular}

\section{Tabla 5}

El Colegio deberá establecer una Sección de Pasantes y estudiantes de la carrera de Contador Público o su equivalente, la cual tendrá los siguientes objetivos:

\begin{tabular}{l}
$\begin{array}{l}\text { Promover el acercamiento profesional, y despertar en } \\
\text { los pasantes y estudiantes el espíritu de solidaridad con } \\
\text { sus compañeros de la carrera de Contador Público. }\end{array}$ \\
\hline $\begin{array}{l}\text { Difundir entre los pasantes y estudiantes tanto los } \\
\text { objetivos que persigue el Colegio, como los derechos y } \\
\text { obligaciones que tienen sus socios. }\end{array}$ \\
\hline Orientarlos en la preparación de su tesis profesional. \\
\hline Estimular a los pasantes distinguidos. \\
\hline $\begin{array}{l}\text { Llevar a cabo diversas actividades para su capacitación } \\
\text { profesional. }\end{array}$ \\
\hline
\end{tabular}

\section{Tabla 6}

La sección de pasantes y estudiantes estará dirigida por una comisión integrada por socios del colegio, el propio Consejo designará al Coordinador de esta sección. siguientes:

Son obligaciones de los Pasantes, las

a) Acatar en lo que les corresponda, el Código de Ética Profesional, las Normas de Actuación Profesional adoptadas por el IMCP, así como estos Estatutos y su Reglamento. 


\section{Comisión de Contabilidad Gubernamental}

Integrada por un director y un secretario, sesión de manera ordinaria en forma mensual e integran a Instituciones de Educación Superior, Académicas, Gubernamentales y Privadas en el desarrollo de los estudiantes y en proceso de educación continua tanto de alumnos como de socios e instituciones invitadas para la formación integral que de paso a la profesionalización de los estudiantes de la Contaduría Pública.

Los Líderes Internacionales de la Profesión Contable identifican los Problemas Principales de 2012. La Encuesta Global 2011 de la IFAC para Líderes Internacionales de la Profesión Contable ha identificado tres factores especialmente preocupantes para la profesión en: el difícil clima financiero global, la mejora de la reputación y credibilidad de la profesión, $\mathrm{y}$ hacer frente a las dificultades de las firmas pequeñas $\mathrm{y}$ medianas $\mathrm{y}$ las pequeñas $\mathrm{y}$ medianas empresas. Observando al respecto la importancia en la mejora de la reputación, que hace necesaria por medio de una mejor educación y conducción.

\section{Formación integral del Contador Público}

\section{Desarrollo profesional inicial - Habilidades Profesionales}

En el mes de mayo de 2019, se publicó en la revista Contaduría Pública, Org. Mx, un interesante artículo que precisa el Desarrollo profesional inicial y las habilidades profesionales, documento que señala que cada profesión requiere, además de conocimientos esenciales, habilidades y ciertas cualidades personales.

Del mismo modo, en la profesión contable, los estudiantes de Contaduría deben poseer ciertas cualidades personales fundamentales que buscan sus empleadores.

El Pronunciamiento Internacional de Formación (PIF 3) forma parte del proceso de Desarrollo Profesional Inicial (DPI) en una Institución de Educación Superior (IES) y es el precepto que describe la competencia profesional requerida en cuanto a las habilidades a desarrollar en los aspirantes a profesionales de la Contaduría.
La intención es que la instrucción que reciban los aspirantes a ser licenciados en Contaduría les permita desarrollar competencias profesionales, que les brinden una perspectiva más amplia y les ayuden a comunicarse de manera efectiva, a realizar investigación, analizar y aplicar el razonamiento lógico y el pensamiento crítico en la solución de problemas.

El PIF 3 especifica las áreas de competencia y los resultados del aprendizaje que describen las habilidades profesionales, siendo estas de tipo:

a) Intelectual: que se refieren a la capacidad de un profesional de la Contaduría para resolver problemas, tomar decisiones y ejercer el juicio profesional.

b) Interpersonal y de comunicación: se refieren a la capacidad de un profesional de la Contaduría para trabajar e interactuar efectivamente con otros.

c) Personal: se refieren a las actitudes y comportamiento de un profesional de la Contaduría.

d) Organizacional: se refiere a la capacidad de un profesional de la Contaduría para trabajar de manera efectiva con o dentro de una organización para obtener los mejores resultados de la gente y de los recursos disponibles.

Competencias para demostrar del aspirante a Contador Público:

Dentro de las habilidades profesionales señaladas en el PIF 3 se recomienda que el aspirante cuente con al menos un nivel de competencia "intermedio", sin embargo, puede presentar avances escalonados que le permitan demostrar un nivel avanzado. Si bien existe poca evidencia empírica alrededor del mundo en cuanto al proceso y resultados del desarrollo de habilidades profesionales en estudiantes de contaduría, principalmente a la luz de los pronunciamientos internacionales, existe una vasta documentación acerca de la importancia que ha tomado el tema de desarrollo de competencias en diversos países. 
Los estudios que investigan las habilidades que un contador profesional necesitará en un futuro, señalan como relevantes las relacionadas con el uso de la tecnología de la información, el trabajo en equipo, el pensamiento analítico, así como las de escritura y comunicación.

\section{Formación.}

Pronunciamientos Internacionales de

Por su parte, la presencia de valores, ética y moral es considerada de alta importancia en las actividades desarrolladas por los profesionales de la contaduría. Algunos otros estudios que señalan mejores prácticas para el desarrollo de la profesión contable sugieren incrementar la oferta de seminarios de educación continua y fortalecer la cooperación entre los actores involucrados en la preparación de las competencias, tal es el caso de los sectores gubernamentales, académicos y profesionales. Un área de oportunidad que observamos en este pronunciamiento es la inclusión de ejemplos prácticos que puedan contribuir en el desarrollo de cada área de competencia en el nivel esperado. En este mismo sentido, sería de gran utilidad para los organismos miembros de la IFAC y las IES, contar con casos de éxito de países que han adoptado los pronunciamientos internacionales de formación señalando los principales retos que han enfrentado, así como las estrategias de implementación utilizadas.

En cuanto al proceso de desarrollo profesional inicial, existe un gran reto por parte de las IES para comprender los diferentes resultados del aprendizaje que señala el PIF 3 y plantear acciones concretas a implementar en materias, talleres y demás actividades necesarias para lograr el nivel de aptitud mínimo estipulado en la normativa. Si bien cada IES posee una filosofía y características particulares que influirán en el perfil de sus estudiantes, se les sugiere incluir en sus programas de estudio, asignaturas y actividades que promuevan el reforzamiento de al menos las habilidades profesionales mencionadas en este pronunciamiento. Por ejemplo, por medio de materias optativas profesionalizantes en las que los alumnos se enfrenten a soluciones de estudios de caso que simulen situaciones que pueden ocurrir en el lugar de trabajo.
Otra forma de llevar a cabo esta labor se realiza por medio de la organización de concursos universitarios, tales como la elaboración de ensayos, trabajos de investigación, solución de casos, debates, entre otros, que promuevan el desarrollo de habilidades. Los Colegios de Contadores Públicos también pueden incluir capacitación no solo técnica, sino de habilidades tales como de escritura-redacción, de comunicación efectiva tanto en español como en inglés, colaboración en equipos de trabajo, metodología de la investigación, liderazgo y uso de tecnologías de la información. Es recomendable que mediante las firmas de contadores y empresas en general, se promuevan actividades que evalúen las habilidades desarrolladas en los estudiantes. Ejemplo de esto son los eventos de detección de talento y campañas de reclutamiento, que requieren a los estudiantes la solución de casos de estudio reales o hipotéticos en un entorno muy similar a la realidad, evaluando la aplicación de conocimientos técnicos, la capacidad de trabajar en equipo bajo presión, así como la capacidad de escribir y exponer propuestas de solución. Adicionalmente, cada IES puede implementar actividades en diferentes etapas del DPI (por ejemplo, a finalizar cada tercio de la carrera) que evalúen las habilidades alcanzadas en los estudiantes y les permita tener retroalimentación de su proceso desarrollado.

\section{Conclusiones}

Hablar de la calidad educativa en México, permite reflexionar sobre una interrogante que la sociedad demanda. ¿Qué hacemos en la gestión directiva para lograr una formación integral, con valores y resultados?, ¿Que hacemos los profesionales de la Contaduría Pública en la actividad docente por los jóvenes del mañana que hoy solicitan espacios laborales y lugares donde tengan voz y voto, donde sean reconocidos sus derechos y sus necesidades de aprender e interactuar con integrantes de Instituciones Educativas y Organizaciones Profesionales? Donde se les dé la oportunidad de mejorar la calidad de su educación, reforzar sus competencias y hacer realidad sus sueños. 
En este documento se resume una experiencia viva que a partir de los trabajos colaborativos por parte del cuerpo docente de las Instituciones de Educación Superior: Instituto Irapuato, Universidad Tecnológica de Tijuana y el Centro de Estudios Superiores del Rosario, de la Universidad Autónoma de Sinaloa, realizados al interior de las Universidades materia de estudio en apoyo de la Comisión Gubernamental del Colegio de Contadores Públicos de Baja California, A.C, y del Colegio de Contadores Públicos de Irapuato, así como del Colegio de Profesionistas en Contaduría Pública del Sur de Sinaloa, A.C. así como la filosofía directiva de trabajo y gestión de la carrera de Contaduría en concordancia del modelo educativo de estas universidades participantes (UII, UTT, CESUR de la UAS) .

Fortalecer el proceso educativo no solo es dentro del aula, ya que en diversas ocasiones el docente, tutor o asesor, no cuenta con la certificación en las disciplinas contables, no pertenece a organizaciones profesionales o no tiene la experiencia de haber conducido la dirección de alguna empresa, por lo tanto es necesario trabajar de la mano con organizaciones profesionales que tengan la experiencia y trabajen bajo marco regulatorio y sólida estructura, principios y valores, que permitan construir una sociedad cada vez mejor preparada que le de sustento al desarrollo económico y social de los futuros profesionales y se consolide el campo de la Contaduría Pública como una disciplina que siga siendo de reconocido prestigio que promueve el desarrollo de las organizaciones y en este caso de los estudiantes de Contaduría Pública, en el camino de la Profesionalización y bajo el encausamiento del marco regulatorio del Instituto Mexicano de Contadores Públicos.

El PIF 3 plantea un alto estándar de calidad que invita a reflexionar y trabajar por una formación integral del Contador Público que complemente los conocimientos técnicos con habilidades, actitudes y valores para desempeñarse con éxito en su vida profesional.

\section{Referencias}

Campas Jairo La función administrativa y la retención estudiantil en la Universidad Santiago de Cali. P. 13

Código de Ética Profesional 11va. Edición, file://le:/instituo\%20irapuato\%20uii/instituto\% 20irapuato\%20escolarizada/academia $\% 20 \mathrm{lcf} / \mathrm{se}$ mestre\%20julio\%20-

$\% 20$ dic $\% 202019 /$ maraton\%20de\%20etica\%202 019\%20imcp/codigo\%20de\%20etica\%2011va \%20edición.pdf.

http://www.alafec.unam.mx/historia.php

García, F., Trejo, M. Flores, L. Rabadán, R. Educación como Formación, Capítulo I, del Libro "La Tutoría" Noriega Editores. Limusa. México, 2007.

Lemaitre María José "Nuevos enfoques sobre el aseguramiento de la calidad en un contexto de cambios" vicepresidenta de INQAAHE, Ex Presidenta de RIACES. 2009.

Luis Eugenio Garate Pereza, Director de Posgrados de la EGAD E ITESM Campus Monterrey luis.de.garate@itesm.mx, Coordinador de Posgrados ANFECA

Noemí Vásquez Quevedo. miembro de la comisión mixta de educación. Tecnológico de Monterrey, campus ciudad de México. NVASQUEZ@ITESM.MX.

Página en español contadoresbc.org

Página en español www.alafec.unam.mx/directorio_intern_registr o.php

Página en español www.imcp.org.mx

Página en español. Asociación Nacional de Facultades y Escuelas de Contaduría y Administración, www.anfeca.unam.mx/

Página en español. Asociación Nacional de Facultades y Escuelas de Contaduría y Administración, www.anfeca.unam.mx/.

Página en español. Secretaria de Educación Pública. www.sep.gob.mx/ 
Página en español. Sistema de indicadores institucionales (2011) del Manual de Calidad de la UTT. Consultado en 2012. http//www.uttijuana.edu.mx/

PIF 3 - Revista Contaduría Pública: IMCP | Una publicación ...ContaduriaPublica.org. $\mathrm{mx}$ > 2019/05/01 > pif-3 http://contaduriapublica.org.mx/2019/05/01/pif3/

Revista Contaduría Pública - Revista Contaduría Pública - Núm. 493- 2013. Competencias profesionales de egresados de Contaduría Pública.

Revista Contaduría Pública - Revista Contaduría Pública - Núm. 5- 2010. http://www.monografias.com/trabajos11/conpu/ conpu.shtml. 